\title{
Cementless Bipolar Hemiarthroplasty for Low-energy Intracapsular Proximal Femoral Fracture in Elderly East-Asian Patients: A Longitudinal 10-year Follow-up Study
}

\author{
Masanori Nishi, MD*+, Ichiro Okano, MD*, Takatoshi Sawada, MD*, \\ Natsuki Midorikawa, MD*, Katsunori Inagaki, MD, PhD ${ }^{+}$ \\ Department of Orthopaedic Surgery, Ohta-Nishinouchi Hospital, Fukushima, Japan* \\ Department of Orthopaedic Surgery, Showa University School of Medicine, Tokyo, Japan ${ }^{\dagger}$
}

Purpose: Short-term outcomes following cemented and cementless hemiarthroplasties (HAs) are reported to be comparable, however, long-term outcomes of cementless HA-especially among Asian patients-is limited. We aimed to assess long-term outcomes in elderly East-Asian patients with intracapsular proximal femoral fractures treated with cementless HA.

Materials and Methods: We enrolled 135 patients treated with cementless HA who met our inclusion criteria. We documented bone/implant-related complications (e.g., incidences of revision hip surgery, femoral stem subsidence, dislocation, intraoperative and postoperative periprosthetic fractures, contralateral hip fractures). We included those patients who are still alive 10 years after the index surgery in the final functional analysis of the existence of pain, ambulatory status, and residential status.

Results: The mean age at injury was 78.3 years (range: 60-85 years). At the 10-year follow-up, 26 of the original patients (19.3\%) had survived. During follow-up, revision hip surgery was conducted in two patients (1.5\%). We recorded the incidence of intraoperative fractures, postoperative periprosthetic fractures, and contralateral fractures in two (1.5\%), eight (5.9\%), and six patients (4.4\%), respectively. Among the 10-year survivors, six patients (23.1\% of the survivors) complained of groin pain, but generally reported the pain to be tolerable.

Conclusion: Among elderly East-Asian patients, the incidence of revision surgery after cementless HA may be lower than that in their European counterparts, whereas the incidence of periprosthetic fractures can still be considerably higher. For patients undergoing cementless HA, prevention of such secondary fractures is of critical importance.

Key Words: Hip fractures, Femoral neck fractures, Osteoporosis

Submitted: June 4, 2019 1st revision: July 10, 2019

2nd revision: August 2, 2019 3rd revision: August 7, 2019

Final acceptance: August 7, 2019

Address reprint request to

Ichiro Okano, MD

[https://orcid.org/0000-0003-1741-5176]

Department of Orthopaedic Surgery, Ohta-Nishinouchi Hospital,

2-5-20 Koriyama, Fukushima 963-8558, Japan

TEL: +81-24-925-1188 FAX: +81-24-925-7791

E-mail: ichiro.okano.e31बgmail.com
This is an Open Access article distributed under the terms of the Creative Commons Attribution Non-Commercial License (http://creativecommons. org/licenses/by-nc/4.0) which permits unrestricted non-commercial use, distribution, and reproduction in any medium, provided the original work is properly cited. 
Masanori Nishi et al. Cementless Hemiarthroplasty for Intracapsular Proximal Femoral Fracture in Elderly East-Asian

\section{INTRODUCTION}

Osteoporotic hip fractures are common enough to have a considerable impact on the healthcare system. Although hip fractures are commonly known to negatively affect the life expectancy of patients ${ }^{1,2}$, like the overall population, these patients have also begun to live longer because of improvements of general health status, and possibly, the advancement of patient care ${ }^{3,4)}$.

Hemiarthroplasty (HA) is a common procedure for displaced intracapsular proximal femoral fracture (ICPF) and allows early full weight-bearing and functional rehabilitation. Limited studies have addressed the longterm outcomes of elderly patients with low-energy fractures treated with HA, however, given the current situation in many developed countries (i.e., aging populations), this issue now urgently demands attention. Two implant fixation techniques exist (i.e., cemented, cementless) and in the short term, both techniques are reported to have comparable functional results ${ }^{5.8}$. Cemented HA is reportedly associated with: i) less thigh pain ${ }^{9,10}$, ii) better mobility ${ }^{11}$, and iii) a lower frequency of periprosthetic fractures ${ }^{6,12,13)}$. However, other studies have shown that cementless prostheses were associated with: i) a shorter operative time, ii) less blood loss ${ }^{2,14-16)}$, iii) less complicated revision surgery ${ }^{17}$, iv) lower perioperative mortality, and v) no risk of bone cement implantation syndrome ${ }^{18-21}$. Long-term studies (>10-years) predominantly involve cemented $\mathrm{HA}^{22-24)}$; information about the long-term outcomes following cementless HA is limited. Furthermore, to the best of our knowledge, all mid- to long-term studies of HA in the English literature are limited to those from European countries, the ability to extrapolate these findings to individuals from East Asia remains unclear.

In this study, we aimed to assess implant survivorship (primary outcome) among elderly East-Asian patients who underwent cementless HA for low-energy ICPF and to evaluate procedure-related complications and functional outcomes among long-term survivors (secondary outcomes).

\section{MATERIALS AND METHODS}

The Institutional Review Board of Ohta-Nishinouchi Hospital approved this study which involved a retrospective chart review of 250 consecutive ICPF patients treated surgically between 2001 and 2007 at Ohta-Nishinouchi Hospital (Nishinouchi No. 26). Of these cases, we excluded those with the following conditions: i) internal fixation
( $n=43)$, ii) cemented HA ( $n=24)$, iii) age of initial injury under 60 years $(n=10)$, iv) high-energy trauma $(n=4), v)$ patients followed-up at an outside institution $(\mathrm{n}=30)$, and vi) missing data $(n=4)$. In total, 135 cases of cementless HA were included in this analysis.

All patients in the study period were treated with bipolar head HA via the posterior approach ${ }^{25}$. During the study period at the institution, cementless HA was the standard or first-choice procedure, and cemented HA was performed only for cases with a trochanteric extension of the fracture, severe osteoporosis, or pre-existing deformity of the hip. We utilized a double wedge, metaphyseal filling stem as the first-choice implant when performing HA for osteoporotic fractures, unless preoperative templating revealed the shape of the proximal femur was mismatched to the type. The choice of specific implant within the same implant type was based on the treating surgeon's discretion. During the study period, all operations were performed by or under the direct supervision of board-certified orthopedic surgeons who had at least 5 years of experience in HA for hip fracture. From the first postoperative day, patients were mobilized and allowed full weight-bearing under supervision of a physiotherapist, unless an intraoperative fracture had occurred or the stability of the femoral component was in doubt. As standard protocol at the institution, patients were instructed-as far as their medical condition allowed-to visit the outpatient department at least once in the first 3 months, then every 6 months for the following 12 months, and once a year thereafter, or more frequently, based on the discretion of the treating physicians.

In all cases, we documented bone- or implant-related complications, including i) revision hip surgery for any cause with or without revision arthroplasty, ii) radiographic loosening/subsidence of the stem over $5 \mathrm{~mm}^{26}$, iii) dislocation of the HA head, iv) intraoperative fracture-defined as any fracture in the ipsilateral femoral bone recognized during surgery or on radiography immediately after the surgery, v) postoperative peri-prosthetic fracture, and vi) contralateral hip fracture. We also included surviving patients who were followed-up 10 years after the index surgery in the assessment of their functional states for pain, ambulation (bedridden, wheelchair, walker, cane, or without any aid), and residence (home, nursing facility, or hospital) as outcome measures.

We defined patients who were alive during at least 10 years of follow-up as a survivor and those who were deceased or lost from follow-up for any reason as a nonsurvivor and conducted statistical analyses of any potential differences in baseline demographics between these two 
groups using EZR (Saitama Medical Center, Jichi Medical University, Saitama, Japan) ${ }^{27)}$, a graphical user interface for the R environment (ver. 3.1.1). We used the Fisher's exact test and the Mann-Whitney $U$-test for binary and continuous variables, respectively; $P$-values less than 0.05 bilaterally were considered statistically significant.

\section{RESULTS}

During the follow-up period, patient dispositions were confirmed as deceased $(n=48)$, unable to visit for followup because of: i) severe medical conditions $(n=26)$, ii) a move to a distant place $(n=5)$, and iii) transportation issues or other unknown reasons $(n=30)$. This left 26 surviving patients who were followed-up 10 years after the index surgery in the final analysis. The mean age at injury was 78.3 years (range: $60-85$ years) and at the final follow-up was 85.3 years (range: 74-96 years). The mean follow-up period of survivors was 11.3 years (range: 10-15 years). Compared to patients who did not survive, surviving patients: i) were younger at the time of injury, ii) included more female patients, and iii) had a lower preoperative American Society of Anesthesiologists grade (Table 1).

The implants used during the study period were Natural Hip $^{\mathbb{R}}$ (Type 2 [double wedge] ${ }^{28)}$; Zimmer Biomed, Warsaw, IN, USA; n=93), Synergy select II $^{\circledR}$ (Type 2; Smith \& Nephew, Memphis, TN, USA; $n=20$ ), CKA $^{\circledR}$ (Type 2; KYOCERA Medical, Osaka, Japan; $n=6)$, Bicontact ${ }^{\circledR}$ (Type 3A [tapered and round] ${ }^{28)}$; Aesculap, Tuttlingen, Germany; $n=3$ ), Alloclassic ${ }^{\mathbb{R}}$ (Type 3C [tapered and rectangular]) ${ }^{28)}, \mathrm{ODC}^{\circledR}$ (Type 3A [tapered and round ${ }^{28)}$; Ortho Development, Draper, UT, USA; n=3), AML plus ${ }^{\circledR}$ (Type 4 [cylindrical and fully coated] ${ }^{28)}$; DePuy Synthes, Warsaw, IN, USA; n=3, Zimmer Biomed; $n=2)$, Meridian ${ }^{\circledR}$ (Type 2; Stryker, Kalamazoo, MI, USA; n=2), Reliance ${ }^{\circledR}$ (Type $3 \mathrm{~A}^{28)}$; Stryker, Kalamazoo; $\mathrm{n}=1$ ), VerSys ${ }^{\mathbb{R}}$ (Type 2; Zimmer Biomed; n=1), and VECTOR-Titan ${ }^{\mathbb{R}}$ (Type 1 [single wedge] ${ }^{28)}$; B.BRAUN, Melsungen, Germany; $n=1$ ).

In terms of bone- or implant-related complications, one survivor underwent revision total hip arthroplasty because of the central migration of the bipolar head 15 years after HA. The patient had no history of osteoarthritis of the

Table 1. Patient Demographics

\begin{tabular}{|c|c|c|c|}
\hline Variable & Long-term survivor & Non-long-term survivor & $P$-value \\
\hline No. of patient & 26 & 109 & \\
\hline Mean follow-up (yr) & $11.3(10-15)$ & $2.7(0-9)$ & \\
\hline Mean age of trauma & $72.3(62-85)$ & $79.5(60-101)$ & $<0.001^{*}$ \\
\hline Sex (male:female) & $3: 23$ (11.5:88.5) & $35: 74$ (32.1:67.9) & $0.049 *$ \\
\hline Chronic steroid use & $3(11.5)$ & $6(5.5)$ & 0.347 \\
\hline Fracture side (right:left) & $13: 13(50.0: 50.0)$ & $64: 45$ (58.7:41.3) & 0.558 \\
\hline \multirow[t]{4}{*}{ Garden grade } & I: 2 (7.7) & I: 4 (3.7) & 0.598 \\
\hline & II: $1(3.8)$ & II: 4 (3.7) & \\
\hline & III: 7 (26.9) & III: 24 (22.0) & \\
\hline & IV: 16 (61.5) & IV: $77(70.6)$ & \\
\hline \multirow[t]{5}{*}{ ASA classification } & I: 3 (11.5) & I: 4 (3.7) & $0.007^{*}$ \\
\hline & II: 20 (76.9) & II: 57 (52.3) & \\
\hline & III: 3 (11.5) & III: 45 (41.3) & \\
\hline & IV: $0(0)$ & IV: $3(2.8)$ & \\
\hline & $V: 0(0)$ & $V: 0(0)$ & \\
\hline \multirow[t]{5}{*}{ Pre-injury ambulatory status } & Without walking aid: 20 (76.9) & Without walking aid: 61 (56.0) & 0.094 \\
\hline & Cane: 5 (19.2) & Cane: $17(15.6)$ & \\
\hline & Walker: 1 (3.8) & Walker: 26 (23.9) & \\
\hline & & Wheelchair-bound: 4 (3.7) & \\
\hline & & Bedridden: 1 (0.9) & \\
\hline \multirow[t]{4}{*}{ Pre-injury residential status } & Home: 25 (96.2) & Home: 88 (80.7) & 0.407 \\
\hline & Nursing facility: 1 (3.8) & Nursing facility: $11(10.1)$ & \\
\hline & & Hospital: 6 (5.5) & \\
\hline & & Unknown: 4 (3.7) & \\
\hline
\end{tabular}

Values are presented as number only, median (range), or number (\%). The sum of the percentages does not equal $100 \%$ because of rounding. ASA: American Society of Anesthesiologists

* The asterisks indicate a statistically significant difference $(P<0.05)$. 


\section{Hip \& Pelvis}

Masanori Nishi et al. Cementless Hemiarthroplasty for Intracapsular Proximal Femoral Fracture in Elderly East-Asian

hip before the index surgery and demonstrated painful osteolysis of the acetabular bone (Paprosky type $2 \mathrm{~B}^{29)}$; Fig. 1 and 2). In one non-survivor, the Girdlestone

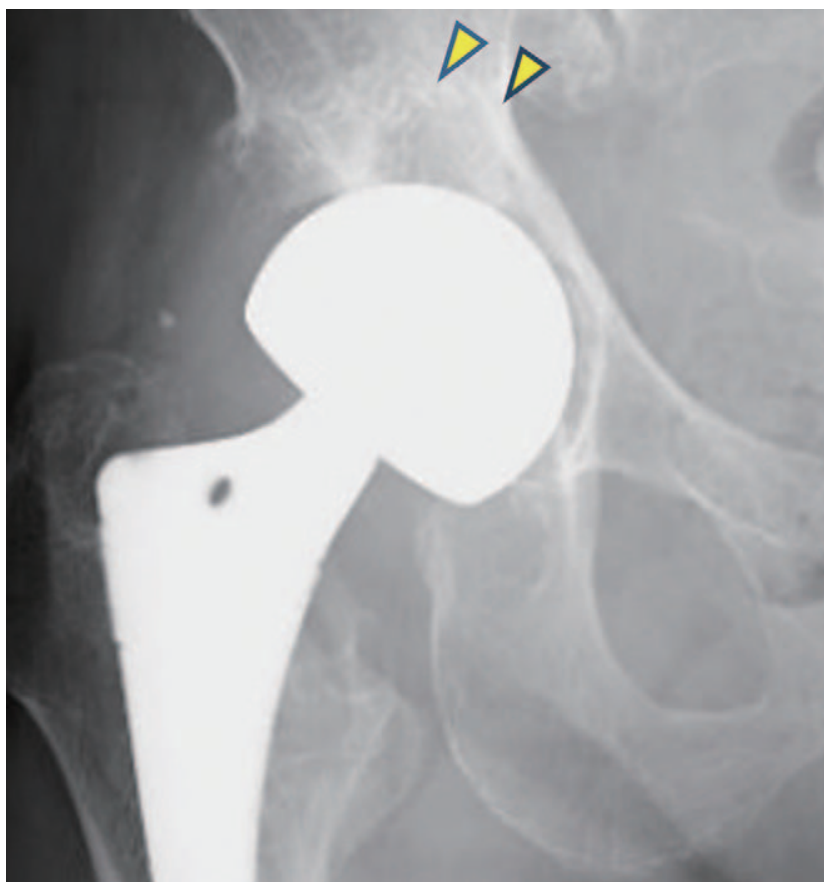

Fig. 1. A radiograph of the right hip of a 77-year-old female patient with a 15-year history of ipsilateral cementless hemiarthroplasty showing an osteolysis in the acetabulum (arrowheads).

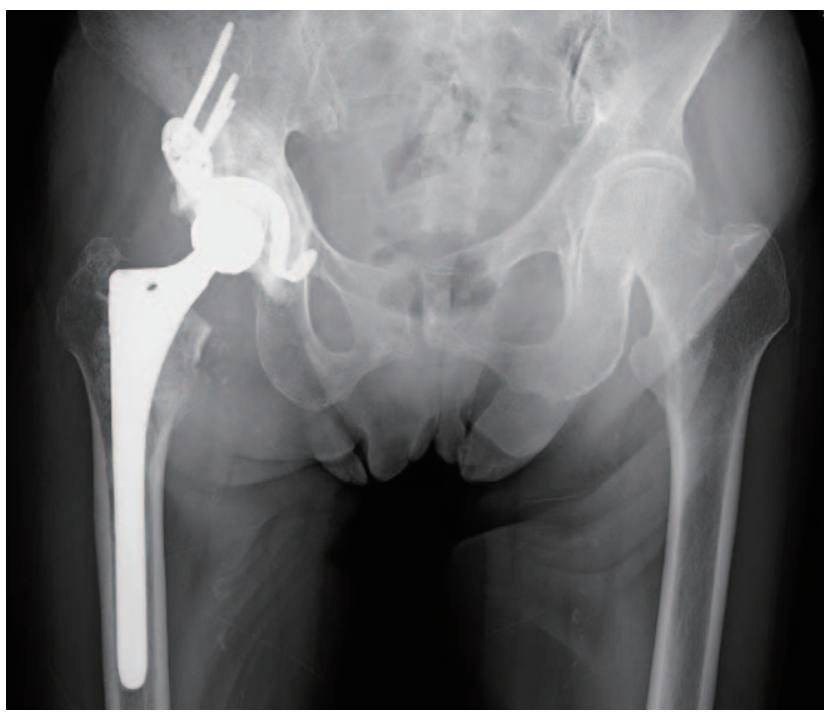

Fig. 2. A radiograph of the bilateral hips after revision total hip arthroplasty. An acetabular reconstruction with Kerboulltype plate and a calcar reconstruction with corticocancellous bone allograft and hydroxyapatite mesh-form sheet were performed. procedure for septic loosening of the HA stem was conducted. The total revision rate was $1.5 \%$ (2/135). Six patients experienced asymptomatic sinking of the cementless stem, but no intervention was required $(4.4 \%, 6 / 135)$. Only five non-survivors $(3.7 \%, 5 / 135)$ presented with dislocation of the HA head; closed reduction was successfully achieved in all cases. No recurring dislocations requiring surgical intervention occurred. We observed intraoperative fracture only in non-survivors (Vancouver ${ }^{30}$ type A:3, C:1). In three cases of Vancouver type A, these fractures were noticed during the HA procedure, and the patients were treated with additional cerclage wiring performed simultaneously. In the first postoperative radiograph taken immediately after the surgery, one patient with undisplaced Vancouver type $\mathrm{C}$ was diagnosed and treated conservatively. Overall, there were eight instances of postoperative periprosthetic fractures $(5.9 \%, 8 / 135)$ : four cases among survivors and four cases among non-survivors. Among the survivors, three cases were classified as Vancouver type A and

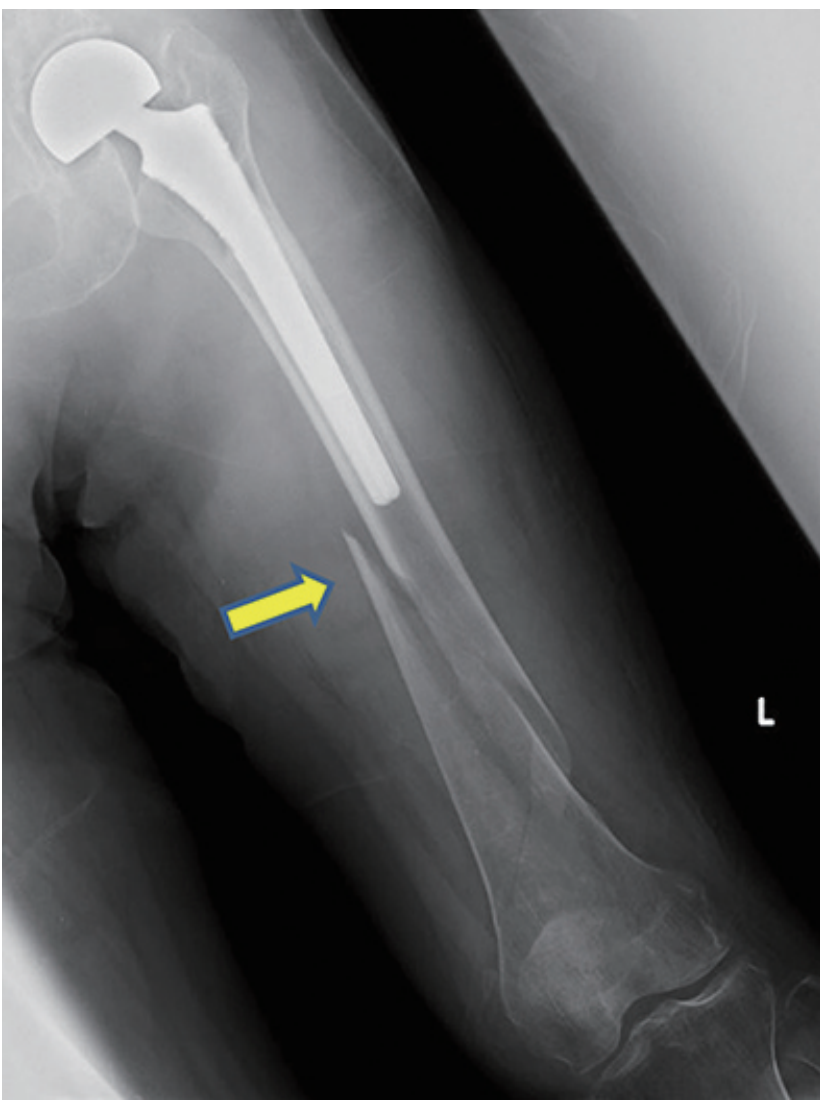

Fig. 3. Spiral fracture lines shown at the mid-distal part of the femur (arrow). A radiograph of the left femur of a 92year-old female patient with an 11-year history of ipsilateral cementless hemiarthroplasty after a fall showing Vancouver type B1 periprosthetic fracture. 


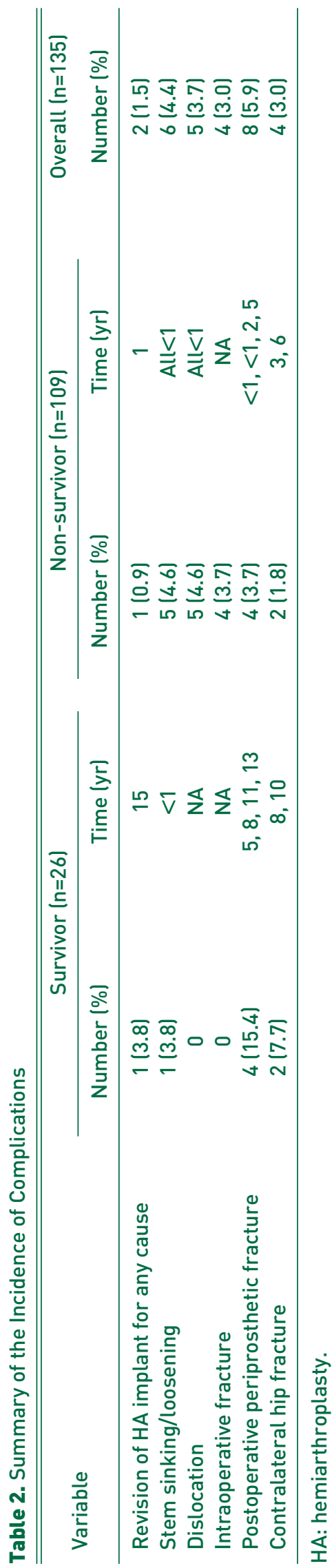

conservatively treated. The other case among the survivors was classified as Vancouver type B1 and required internal fixation with a plate (Fig. 3). All four non-surviving patients with periprosthetic fracture were conservatively treated. Of these, three patients had a Vancouver type A fracture, and one had a type B fracture. The patient with a type B fracture was considered inoperable because of concomitant respiratory distress. In two survivors and two non-survivors, contralateral hip fractures were observed during the followup period $(3.0 \%, 4 / 135$; Table 2$)$.

Among survivors from whom ambulatory status information was available, six had secondary fractures (periprosthetic or contralateral), and two previously ambulating patients had become non-ambulatory after secondary injuries (7.7\% of total survivors [2/26], 33.3\% of patients [2/6] with secondary fractures). One of these two patients had a Vancouver type A periprosthetic fracture, and the other had a contralateral femoral trochanteric fracture.

An analysis of 10-year functional outcomes among survivors revealed that six patients $(23.1 \%)$ complained of pain around the injured hip, but reported the intensity of pain was mild in most cases; only one patient required oral analgesics. Two patients experienced periprosthetic fractures, and no patient experienced femoral component subsidence or other complications. Twenty patients (76.9\%) were still able to walk. Two cases had become wheelchairbound, and two cases were bedridden. While 22 patients $(84.6 \%)$ resided at home, four resided in nursing homes (Table 3).

\section{DISCUSSION}

In our study, $19.3 \%$ of the included patients were followedup for over 10 years. Previous studies showed a mortality rate 1 year after hip fracture of $20 \%$ to $30 \%^{14,31)}$ and 10 year survival rates are reported to be $15 \%$ to $32.9 \%^{15,16,32)}$. To the best of our knowledge, this is the first reported longterm study on cementless HA in an Asian population in the English literature. Even including all drop-out cases in the denominator, the survival rate in our study was comparable to that of previous studies. Our surviving patients were younger and healthier than those who did not reach the 10-year follow-up mark (i.e., non-survivors), and these trends were similar to those in a previous report by Chatterton et al. ${ }^{31}$.

In this study, only two cases of revision were required, a revision rate lower than that in previous reports. Only 
Hip \& Pelvis

Masanori Nishi et al. Cementless Hemiarthroplasty for Intracapsular Proximal Femoral Fracture in Elderly East-Asian

Table 3. Outcomes of Pain, Ambulatory Status, and Residential Status

\begin{tabular}{|c|c|c|c|}
\hline \multirow{2}{*}{ Variable } & \multicolumn{3}{|c|}{ Time of examination } \\
\hline & Pre-injury & 3 months & 10 years \\
\hline \multirow[t]{2}{*}{ Pain } & $1 / 26$ & $15 / 26$ & $6 / 26$ \\
\hline & $\begin{array}{l}\text { Oral analgesics: } 1 / 26 \\
\text { (for concomitant osteoarthritis) }\end{array}$ & Oral analgesics: $1 / 26$ & Oral analgesics: $1 / 26$ \\
\hline \multirow[t]{4}{*}{ Ambulatory status } & Without walking aid: 20 & Without walking aid: 1 & Without walking aid: 2 \\
\hline & Cane: 5 & Cane: 23 & Cane: 15 \\
\hline & Walker:1 & Wheelchair-bound: 2 & Walker: 3 \\
\hline & & & $\begin{array}{l}\text { Wheelchair-bound: } 3 \\
\text { Bedridden: } 3\end{array}$ \\
\hline \multirow[t]{3}{*}{ Residential status } & Home: 25 & Home: 22 & Home: 22 \\
\hline & Nursing facility: 1 & Rehabilitation facility: 2 & Nursing home: 4 \\
\hline & & & Nursing facility: 2 \\
\hline
\end{tabular}

Values are presented as number only.

a few studies have reported differences between over 5year results for cemented and cementless HAs. Summarizing these previous reports (Table 4), the 10-year revision rates among survivors were up to $8.8 \%$ in cementless HAs and $2.4 \%$ to $3.5 \%$ in cemented HAs. In a retrospective study of HA patients older than 75 years of age with a follow-up of 12 to 19 years, Viberg et al ${ }^{32)}$ reported the hazard ratio of reoperation among patients treated with cemented HA as lower than that of patients with cementless HA. Most patients in these previous reports had revision arthroplasty within 5 years. Within the same time span, in our study, there was only one $(0.9 \%)$ revision (for septic loosening). This lower incidence of revision hip surgery might be the result of difference in bodily habits and/or the lower prevalence of pre-clinical chondral injury in the acetabulum among East-Asians compared with Europeans. According to total hip arthroplasty studies, high body mass index $(\mathrm{BMI})^{33)}$ or body weight ${ }^{34}$ are associated with the risk of revision surgery after arthroplasty. Relatively low BMI and body weight among Asian patients might have a protective effect against symptomatic failure after HA. Additionally, a recent review reported that the prevalence of primary osteoarthritis of the hip is substantially higher, probably because of some genetic reasons, among European patients than that in other races; the prevalence was found to be 60 to 120 per million among European populations, whereas that in Asian population was $<10$ per million ${ }^{355}$. Furthermore, studies on osteonecrosis of the femoral head demonstrated that acetabular cartilage degenerative changes are commonly observed in patients with osteonecrosis of the femoral head, even when radiographs of the acetabulum appear normal ${ }^{36}$. In such cases, evidence showed that HA resulted in unacceptably high failure rates, mainly due to central migration of the prosthetic femoral head ${ }^{37,38}$. Thus, it is suggested that pre-exiting acetabular cartilage lesions are more prevalent among European fracture patients, and a certain proportion of these lesions appears normal on radiographs eventually leading to high failure rate after HA.

In our study, the intraoperative fracture rate was 3.0\%, which is comparable to the majority of other studies (range: 2.3-3.0\% $\left.{ }^{39,40}\right)$. On the other hand, Chana et al. ${ }^{41)}$ reported higher incidences of intraoperative fractures among patients who underwent cemented or cementless HAs: $5.9 \%$ and $15.2 \%$, respectively. They concluded that cementless HA was a risk factor for intraoperative fracture. We believe this may have been caused by a technical issue in their procedure or the implant they used.

The incidence of postoperative periprosthetic fractures was reported to be higher among patients with cementless HA than that among patients with cemented HA (at 5 years, $5.7-15.2 \%$ in cementless and $0.9-5.9 \%$ in cemented ${ }^{8,13,41,42}$. In these reports, periprosthetic fractures occurred mostly within 5 years. Viberg et al ${ }^{32}$ also found most reoperation cases to be due to periprosthetic fractures (they did not demonstrate the exact percentages of underlying conditions) and $89.4 \%$ (42/47) of the total reoperation cases to be required within 5 years. In our cohort, although the overall incidence of periprosthetic fracture was $8.9 \%$, only $6.7 \%$ (9/135) of patients experienced a periprosthetic fracture (including intraoperative fractures) within 5 years. Although this was high, the 5-year incidence of periprosthetic fracture was nevertheless lower than reported previously. The high intraoperative or early periprosthetic fracture rates in previous 


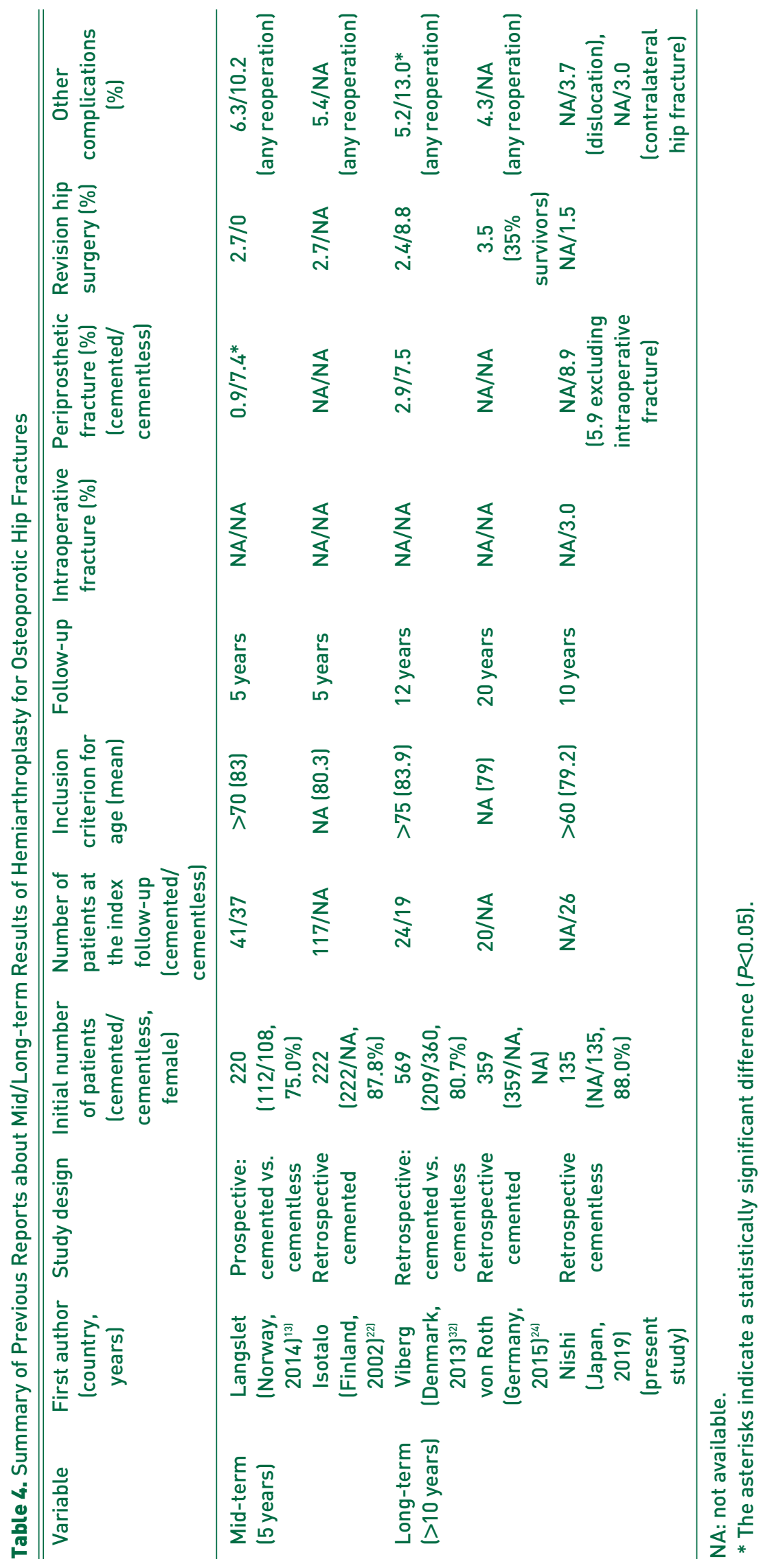

studies may be attributed to the technical challenges of surgery and/or the implant design during those earlier study periods.

Furthermore, in the follow-up period, $3.0 \%$ of our patients had contralateral hip fractures. Secondary hip fractures reportedly occurred in $2 \%$ to $5 \%$ of the proximal femoral fracture patients within one year of the initial injury ${ }^{43-46}$, and the highest risk of secondary hip fractures occurred in the first postoperative year ${ }^{47,48}$. In our study, no patient had a contralateral fracture within 1 year. No studies of mid- to long-term results of HA mention contralateral fractures, but a patient's functioning can be greatly impacted by contralateral fracture. In our cohort, one of two contralateral hip fracture patients became non-ambulatory after the secondary injury; we believe that this issue cannot be ignored and should be addressed in future preventive studies.

An analysis of the 10-year functional status data revealed that most surviving patients were functionally able, and $76.9 \%$ of patients were pain-free or with occasional and/or mild pain which did not require analgesics. Our analysis of ambulation status suggested that longterm postoperative ambulatory and residential states were determined roughly within 3 months following the index surgery. Zhang et al. ${ }^{49}$ reported the effectiveness of intensive rehabilitation programs in the early recovery phase ( $<3$ weeks) on the mobility of elderly patients with a femoral neck fracture, and their results indicated that the efficacy of early intense rehabilitation was maintained even at 1 year after surgery. Our results were consistent with their findings. Although functional outcomes are multifactorial, our results also highlight the importance of early rehabilitation for long-term functional results.

Because of the study design and 
characteristics of the patient population, this study inherently included several limitations. The first and biggest was the small, retrospective, single-center nature of our study, with no control. Additionally, detailed functional outcomes were only available for patients with over 10-year follow-up and we could not include several patient factors in detail (e.g., accessibility to rehabilitation facility in the assessment of functional outcome, complications). In this study, the surgical experience of the treating surgeons and choice of the implant, which might affect clinical outcomes, were not controlled. Lastly, the drop-out rate was considerable. The institution in which the study was conducted is located in a rural area with an elderly (over 65 years) population ratio of over $30 \%$; more than half of these people lived alone or only with their spouses. Because the institution was the only tertiary referral center with well-functioning trauma service in that area, patients with conditions which required an immediate medical attention (e.g., dislocation, secondary fractures), were likely transferred to the institution; the results of analyses might have underestimated the proportions of complications among non-survivors because of this follow-up issue. Because of transportation issues and patients' medical/cognitive conditions, the follow-up is a major barrier for studies evaluating long-term outcomes in elderly patients ${ }^{50,51)}$. However, we strongly believe that such isolated elderly people can receive inestimable benefit from maintaining their mobility; thus, a further, direct, comparative study, with a proper follow-up strategy, is necessary to make robust recommendations.

\section{CONCLUSION}

Our results suggest that, among elderly East-Asian patients, the incidence of revision surgery after cementless HA might be lower, whereas the incidence of periprosthetic fractures was consistent with previous reports. Although most patients treated with cementless HA were functionally capable 10 years after the initial injury, a considerable percentage of survivors also sustained periprosthetic fractures and contralateral hip fractures.

\section{CONFLICT OF INTEREST}

The authors declare that there is no potential conflict of interest relevant to this article.

\section{REFERENCES}

1. Alexiou KI, Roushias A, Varitimidis SE, Malizos KN. Quality of life and psychological consequences in elderly patients after a hip fracture: a review. Clin Interv Aging. 2018;13:143-50.

2. Schrøder HM, Erlandsen M. Age and sex as determinants of mortality after hip fracture: 3,895 patients followed for 2.5-18.5 years. J Orthop Trauma. 1993;7:525-31.

3.Zhang BF, Wang PF, Huang H, Cong YX, Wang H, Zhuang $\mathrm{Y}$. Interventions for treating displaced intracapsular femoral neck fractures in the elderly: a Bayesian network meta-analysis of randomized controlled trials. Sci Rep. 2017;7:13103.

4. Mittal R, Banerjee S. Proximal femoral fractures: principles of management and review of literature. J Clin Orthop Trauma. 2012;3:15-23.

5. Manoharan G, Chatterton BD, Moores TS, Roberts PJ. Uncemented Thompson's hemiarthroplasty: safe, palliative and cost-effective surgery in the infirm patient-a consecutive series of 1445 cases. Eur J Orthop Surg Traumatol. 2018; 28:1103-9.

6. Yli-Kyyny T, Sund R, Heinänen M, Venesmaa P, Kröger $\mathrm{H}$. Cemented or uncemented hemiarthroplasty for the treatment of femoral neck fractures? Acta Orthop. 2014;85:49-53.

7.Bell KR, Clement ND, Jenkins PJ, Keating JF. A comparison of the use of uncemented hydroxyapatite-coated bipolar and cemented femoral stems in the treatment of femoral neck fractures: a case-control study. Bone Joint J. 2014:96:299-305.

8. Deangelis JP, Ademi A, Staff I, Lewis CG. Cemented versus uncemented hemiarthroplasty for displaced femoral neck fractures: a prospective randomized trial with early follow-up. J Orthop Trauma. 2012;26:135-40.

9. Ng ZD, Krishna L. Cemented versus cementless hemiarthroplasty for femoral neck fractures in the elderly. J Orthop Surg (Hong Kong). 2014;22:186-9.

10. Shewale SB, Pandit HG, Latham JM. Hemiarthroplasty: to cement or not to cement? A preliminary report. Hip Int. 2004;14:189-92.

11. Parker MI, Pryor G, Gurusamy K. Cemented versus uncemented hemiarthroplasty for intracapsular hip fractures: a randomised controlled trial in 400 patients. J Bone Joint Surg Br. 2010; 92:116-22.

12. Moerman S, Mathijssen NMC, Niesten DD, et al. More complications in uncemented compared to cemented hemiarthroplasty for displaced femoral neck fractures: a randomized controlled trial of 201 patients, with one year follow-up. BMC Musculoskelet Disord. 2017;18:169.

13. Langslet E, Frihagen F, Opland V, Madsen JE, Nordsletten $\mathrm{L}$, Figved W. Cemented versus uncemented hemiarthroplasty for displaced femoral neck fractures: 5-year followup of a randomized trial. Clin Orthop Relat Res. 2014;472:1291-9.

14. Wagner P, Fuentes P, Diaz A, et al. Comparison of complications and length of hospital stay between orthopedic and orthogeriatric treatment in elderly patients with a hip fracture. Geriatr Orthop Surg Rehabil. 2012;3:55-8.

15. Lin JC, Liang WM. Outcomes after fixation for undisplaced femoral neck fracture compared to hemiarthroplasty for displaced femoral neck fracture among the elderly. BMC 
Musculoskelet Disord. 2015;16:199.

16. van den Bekerom MP, Hilverdink EF, Sierevelt IN, et al. A comparison of hemiarthroplasty with total hip replacement for displaced intracapsular fracture of the femoral neck: a randomised controlled multicentre trial in patients aged 70 years and over. J Bone Joint Surg Br. 2010;92:1422-8.

17. Figved W, Opland V, Frihagen F, Jervidalo T, Madsen JE, Nordsletten L. Cemented versus uncemented hemiarthroplasty for displaced femoral neck fractures. Clin Orthop Relat Res. 2009;467:2426-35.

18. de Jong L, Klem TMAL, Kuijper TM, Roukema GR. Factors affecting the rate of surgical site infection in patients after hemiarthroplasty of the hip following a fracture of the neck of the femur. Bone Joint J. 2017;99:1088-94.

19. Khan RJ, MacDowell A, Crossman P, Keene GS. Cemented or uncemented hemiarthroplasty for displaced intracapsular fractures of the hip--a systematic review. Injury. 2002;33: $13-7$.

20. Ning GZ, Li YL, Wu Q, Feng SQ, Li Y, Wu QL. Cemented versus uncemented hemiarthroplasty for displaced femoral neck fractures: an updated meta-analysis. Eur J Orthop Surg Traumatol. 2014;24:7-14.

21. Donaldson AJ, Thomson HE, Harper NJ, Kenny NW. Bone cement implantation syndrome. Br J Anaesth. 2009;102: 12-22.

22. Isotalo K, Rantanen J, Aärimaa V, Gullichsen E. The longterm results of Lubinus interplanta hemiarthroplasty in 228 acute femoral neck fractures. A retrospective six-year followup. Scand J Surg. 2002;91:357-60.

23. Tol MC, van den Bekerom MP, Sierevelt IN, Hilverdink EF, Raaymakers EL, Goslings JC. Hemiarthroplasty or total hip arthroplasty for the treatment of a displaced intracapsular fracture in active elderly patients: 12-year follow-up of randomised trial. Bone Joint J. 2017;99:250-4.

24. von Roth P, Abdel MP, Harmsen WS, Berry DJ. Cemented bipolar hemiarthroplasty provides definitive treatment for femoral neck fractures at 20 years and beyond. Clin Orthop Relat Res. 2015;473:3595-9.

25. Moore AT. The self-locking metal hip prosthesis. J Bone Joint Surg Am. 1957;39:811-27.

26. Kabelitz M, Fritz Y, Grueninger P, Meier C, Fries P, Dietrich M. Cementless stem for femoral neck fractures in a patient's 10th decade of life: high rate of periprosthetic fractures. Geriatr Orthop Surg Rehabil. 2018;9:2151459318765381.

27. Kanda Y. Investigation of the freely available easy-to-use software 'EZR' for medical statistics. Bone Marrow Transplant. 2013;48:452-8.

28. Khanuja HS, Vakil JJ, Goddard MS, Mont MA. Cementless femoral fixation in total hip arthroplasty. J Bone Joint Surg Am. 2011;93:500-9.

29. Paprosky WG, Perona PG, Lawrence JM. Acetabular defect classification and surgical reconstruction in revision arthroplasty. A 6-year follow-up evaluation. J Arthroplasty. 1994;9:33-44.

30. Duncan CP, Masri BA. Fractures of the femur after hip replacement. Instr Course Lect. 1995;44:293-304.

31. Chatterton BD, Moores TS, Ahmad S, Cattell A, Roberts PJ. Cause of death and factors associated with early inhospital mortality after hip fracture. Bone Joint J. 2015; 97:246-51.
32. Viberg B, Overgaard S, Lauritsen J, Ovesen O. Lower reoperation rate for cemented hemiarthroplasty than for uncemented hemiarthroplasty and internal fixation following femoral neck fracture: 12- to 19-year follow-up of patients aged 75 years or more. Acta Orthop. 2013;84: 254-9.

33. Wagner ER, Kamath AF, Fruth KM, Harmsen WS, Berry DJ. Effect of body mass index on complications and reoperations after total hip arthroplasty. J Bone Joint Surg Am. 2016;98:169-79.

34. Traina F, Bordini B, De Fine M, Toni A. Patient weight more than body mass index influences total hip arthroplasty long term survival. Hip Int. 2011;21:694-9.

35. Hoaglund FT. Primary osteoarthritis of the hip: a genetic disease caused by European genetic variants. J Bone Joint Surg Am. 2013;95:463-8.

36. Steinberg ME, Corces A, Fallon M. Acetabular involvement in osteonecrosis of the femoral head. J Bone Joint Surg Am. 1999;81:60-5.

37. Hwang KT, Kim YH, Kim YS, Choi IY. Is bipolar hemiarthroplasty a reliable option for Ficat stage III osteonecrosis of the femoral head? 15- to 24-year followup study. Arch Orthop Trauma Surg. 2012;132:1789-96.

38. Muraki M, Sudo A, Hasegawa M, Fukuda A, Uchida A. Long-term results of bipolar hemiarthroplasty for osteoarthritis of the hip and idiopathic osteonecrosis of the femoral head. J Orthop Sci. 2008;13:313-7.

39. Gallinaro P, Tabasso G, Negretto R, Brach del Prever EM. Experience with bipolar prosthesis in femoral neck fractures in the elderly and debilitated. Clin Orthop Relat Res. 1990; (251):26-30.

40. Foster AP, Thompson NW, Wong J, Charlwood AP. Periprosthetic femoral fractures--a comparison between cemented and uncemented hemiarthroplasties. Injury. 2005;36:424-9.

41. Chana R, Mansouri R, Jack $\mathrm{C}$, et al. The suitability of an uncemented hydroxyapatite coated (HAC) hip hemiarthroplasty stem for intra-capsular femoral neck fractures in osteoporotic elderly patients: the Metaphyseal-Diaphyseal Index, a solution to preventing intra-operative periprosthetic fracture. J Orthop Surg Res. 2011;6:59.

42. Robinson CM, Adams CI, Craig M, Doward W, Clarke MC, Auld J. Implant-related fractures of the femur following hip fracture surgery. J Bone Joint Surg Am. 2002;84:1116-22.

43. Hagino H, Sawaguchi T, Endo N, Ito Y, Nakano T, Watanabe Y. The risk of a second hip fracture in patients after their first hip fracture. Calcif Tissue Int. 2012;90:14-21.

44. Yamanashi A, Yamazaki K, Kanamori M, et al. Assessment of risk factors for second hip fractures in Japanese elderly. Osteoporos Int. 2005; 16:1239-46.

45. Vochteloo AJ, Borger van der Burg BL, Röling MA, et al. Contralateral hip fractures and other osteoporosis-related fractures in hip fracture patients: incidence and risk factors. An observational cohort study of 1,229 patients. Arch Orthop Trauma Surg. 2012;132:1191-7.

46. Mitani S, Shimizu M, Abo M, Hagino H, Kurozawa Y. Risk factors for second hip fractures among elderly patients. $J$ Orthop Sci. 2010;15:192-7.

47. Chang JD, Yoo JH, Reddy P, Lee SS, Hwang JH, Kim TY. 


\section{Hip \& Pelvis}

Masanori Nishi et al. Cementless Hemiarthroplasty for Intracapsular Proximal Femoral Fracture in Elderly East-Asian

Risk factors for contra-lateral hip fracture in elderly patients with previous hip fracture. Injury. 2013;44:1930-3.

48. Batin S, Ozan F, Gurbuz K, Koyuncu S, Vatansever F, Uzun E. Evaluation of risk factors for second hip fractures in elderly patients. J Clin Med Res. 2018;10:217-20.

49.Zhang J, Ang ML, Kwek EB. Who will walk again? Effects of rehabilitation on the ambulatory status in elderly patients undergoing hemiarthroplasty for femoral neck fracture. Geriatr Orthop Surg Rehabil. 2015;6:168-72.

50. Knechel NA. The challenges of enrolling older adults into intervention studies. Yale J Biol Med. 2013;86:41-7.

51. Ridda I, MacIntyre CR, Lindley RI, Tan TC. Difficulties in recruiting older people in clinical trials: an examination of barriers and solutions. Vaccine. 2010;28:901-6. 